Atmos. Meas. Tech. Discuss., https://doi.org/10.5194/amt-2017-384

Manuscript under review for journal Atmos. Meas. Tech.

Discussion started: 28 November 2017

(c) Author(s) 2017. CC BY 4.0 License.

(c) (i)

\author{
Atmospheric \\ Measurement \\ Techniques \\ Discussions
}

\title{
Effect of charges carried by atmospheric particles on radar power ratio
}

\author{
Li. XIE ${ }^{1,2}$, Xuebang Gao ${ }^{1,2}$, Jianhu Qin ${ }^{1,2}$ \\ ${ }^{1}$ Key Laboratory of Mechanics on Disaster and Environment in Western China, Ministry of Education, Lanzhou, China \\ ${ }^{2}$ College of Civil Engineering and Mechanics, Lanzhou University, Lanzhou 730000, China \\ 5 Email correspondence to xieli@1zu.edu.cn
}

Abstract. The ratio of the receiving power to the transmitting power (RPR) of a well-designed radar system is determined by the absorption and scattering of materials coming into contact with radar waves along the propagating path of the radar wave. In atmospheric detection by a radar system, the RPR is mainly determined by the absorption and scattering of atmospheric particles. Particle properties, such as the charge carried by particles, will affect the RPR. Particle charging is common in a particle system. The

10 present study investigated the effect of charges carried by atmospheric particles on the RPR. It was found that charges carried by particles can increase the RPR, and the increment is related to the charges, particle size, radar emission frequency, and corresponding refractive index of the particles. As the emission frequency of the radar increases, the effect of the charges on the RPR decreases, and especially, the effect of charges on the RPR can be ignored for lidar used to detect sand particles. The number density of particles based on the RPR without considering charges carried by sand particles will be overestimated relative to that when considering

15 charges carried by sand particles. The overestimation increases with the surface charge density, for the same type of radar.

\section{Introduction}

The detection of atmospheric particles is necessary for such applications such as weather forecasting (Tao et al., 2010; Collis, 2010; Barrett and Bendov, 1967). The type of atmospheric particles usually determines the type of weather; e.g., most atmospheric particles are sand/dust particles in the case of windy/sandy weather and water drops in foggy weather (Gaussiat et al., 2003; Middleton, 2017). Owing to their

20 noninvasive measurements, many advanced technologies based on the scattering of electromagnetic (EM) waves are used to determine properties of atmospheric particles, such as the particle number density (Zhao et al., 2015; Wilson and Brandes, 1979; Mona et al., 2012), with 
Atmos. Meas. Tech. Discuss., https://doi.org/10.5194/amt-2017-384

Manuscript under review for journal Atmos. Meas. Tech.

Discussion started: 28 November 2017

(c) Author(s) 2017. CC BY 4.0 License.

(c) (i)

\section{Atmospheric \\ Measurement \\ Techniques \\ Discussions}

radar technology being mature. Systems that employ microwave radar and lidar are commonly used in many areas of meteorology and atmospheric physics (Ahmed, 2008; Aoki et al., 2016; Muller and Quenzel, 1985).

Atmospheric particles are commonly charged; e.g., sand/dust particles can be electrified when transported by wind, which is the so-called wind-sand electrification phenomenon (Zheng et al., 2003; Zheng et al., 2004). Zheng et al. observed wind-sand electrification in a wind

5 tunnel and found that the charge-to-mass ratio of the mixed sand particle can reach $-1120.7 \mu \mathrm{C} / \mathrm{kg}$ at a height of $0.5 \mathrm{~m}$ and wind speed of 10 $\mathrm{m} / \mathrm{s}$, on the basis of which we calculate a surface charge density reaching $-4.56 \times 10^{-5} \mathrm{C} / \mathrm{m}^{2}$ for sand particles having a radius of $50 \mu \mathrm{m}$ and mass density of $2440 \mathrm{~kg} / \mathrm{m}^{3}$ (Musa et al., 2014). According to Pruppacher and Klett (2003), the amount of elementary charge that can be placed on a droplet ranges from 1 to $10^{8}$, depending on the size of the droplet; i.e., more charge can be placed on a larger droplet. A droplet with a radius of $50 \mu \mathrm{m}$ can carry charge of $1.6 \times 10^{-5} \mu \mathrm{C}$, and the corresponding surface charge density $\sigma=-0.5 \times 10^{-3} \mathrm{C} / \mathrm{m}^{2}$. Bohren

10 et al. theoretically studied the scattering of EM waves by a charged particle and found that the scattering coefficients of particles carrying charges and neutral particles greatly differ (Bohren and Hunt, 2011). Klačka's research group later conducted a series of studies to investigate the scattering/absorption of dust particles, water droplets, and ice grains, finding that charges carried by the particles affect the optical properties of the particles and the scattering/absorption of EM waves when the particle size parameter $(2 \pi r / \lambda$, in which $r$ is the particle radius and $\lambda$ is the EM wavelength) is less than 0.01 (Klačka and Kocifaj, 2007; Klačka. and Kocifaj, 2010; Klačka et al., 2015). The main functions of a

15 radar system are to inversely deduce particle properties, such as the particle size distribution and particle number density using the receiving power for a known transmitting power or the ratio of receiving power to transmitting power (RPR) based on the extinction signal, especially the signal backscattered by particles. Qin and Xie also found that charges carried by a particle affect the backscattering strength in a study on the scattering phase function of a charged particle (Qin and Xie, 2015). In addition, Kocifaj et al. found that an increasing amount of charge on cloud droplets strengthens the backscattering of a radar wave and proposed a remote-sensing method that gives a good warning of a lightning

20 threat (Kocifaj et al., 2015). We therefore infer the charges carried by the particles affect the detection results of the radar system. 
Atmos. Meas. Tech. Discuss., https://doi.org/10.5194/amt-2017-384

Manuscript under review for journal Atmos. Meas. Tech.

Discussion started: 28 November 2017

(c) Author(s) 2017. CC BY 4.0 License.

(c) (i)

\section{Atmospheric \\ Measurement \\ Techniques \\ Discussions}

Motivated by the above, we derive the RPR of radar systems, including a lidar system detecting a particle system in which the particles carry charges on their surfaces in section 2 of the present paper. Section 3 discusses the effect of charges carried by the particles on the RPR for different particle size distributions, the surface charge density, the refractive index of the particles, and the radar emission frequency. Conclusions are drawn from the results of the study in section 4.

\section{2. RPR of a charged-particle system}

A radar detection system transmits an EM wave that propagates through an atmosphere particle system, and the return signal of the EM wave is received usually, but not always, by the same radar system (Mona et al., 2012; Ahmed, 2008), a schematic of which is shown in Fig. 1.

Denoting the receiving power as $P_{r}(\mathrm{~W})$, the transmitting power as $P_{t}(\mathrm{~W})$, the detection range as R, and the beamwidths as $\Delta \phi$ and $\Delta \theta$, the receiving power of a designed radar system can be calculated using the conventional radar equation (Fukao et al., 2014):

$$
P_{r}=P_{t} \frac{G^{2} \lambda^{2} \Delta \phi \Delta \theta \tau c}{2^{10} \ln 2 \pi^{2} R^{2}} \beta \times 10 \int_{0}^{R} \sigma_{e x t} d l / 10
$$

where $G$ is the antenna gain and $\lambda$ and $\tau$ are respectively the wavelength and duration of the emitted EM wave. $\beta$ and $\sigma_{\text {ext }}$ are the backscattering cross-section per unit volume and the attenuation cross-section per unit volume of the atmospheric particles in contact with the EM wave along its propagating path. A lidar system uses a laser EM spectrum. The receiving power is calculated as (Collis, 1970)

$$
P_{r}=P_{t} \frac{\tau c A}{R^{2}} \beta \times \exp \left(-2 \int_{0}^{R} \sigma_{e x t} d l\right)
$$

15 where $\mathrm{A}$ is the area of the receiver aperture. From Eqns. (1) and (2), for a well-designed radar or lidar system, RPR $=P_{t} / P_{t}$ is determined according to the absorption and scattering of the EM wave by the particles (Chiou and Kiang, 2017). The extinction coefficient and backscattering coefficient were derived by Klačka and Kocifai for an EM wave illuminating a single surface-charged particle, illustrated in Fig. 1(b) (Klačka and Kocifaj, 2007):

$$
\begin{aligned}
& Q_{e x t}=\frac{2}{x^{2}} \sum_{n=1}^{\infty}(2 n+1) \operatorname{Re}\left(a_{n}+b_{n}\right) \\
& Q_{b a c}=\frac{1}{x^{2}}\left|\sum_{n=1}^{\infty}(2 n+1)(-1)^{n}\left(a_{n}-b_{n}\right)\right|^{2},
\end{aligned}
$$

20 where $x$ is the particle size parameter, which can be calculated from the particle radius $r$ and the EM wavelength. Re( $\cdot$ ) denotes the real part of a 
Atmos. Meas. Tech. Discuss., https://doi.org/10.5194/amt-2017-384

Manuscript under review for journal Atmos. Meas. Tech.

Discussion started: 28 November 2017

(c) Author(s) 2017. CC BY 4.0 License.

(c) (i)

\section{Atmospheric \\ Measurement \\ Techniques \\ Discussions}

complex number. $a_{n}$ and $b_{n}$ are the Mie scattering coefficients of the scattering field of EM waves for a surface-charged particle without considering the magnetism of the particle material, and are analytically expressed as (Klačka and Kocifaj, 2007; Zhou and Xie, 2011; Bohren and Hunt, 2011)

$$
\begin{gathered}
a_{n}=\frac{\psi_{n}(x) \psi_{n}^{\prime}(m x)-m \psi_{n}^{\prime}(x) \psi_{n}(m x)-i \omega k^{-1} \mu_{0} \sigma_{s} \psi_{n}^{\prime}(x) \psi_{n}^{\prime}(m x)}{\xi_{n}(x) \psi_{n}^{\prime}(m x)-m \xi_{n}^{\prime}(x) \psi_{n}(m x)-i \omega k^{-1} \mu_{0} \sigma_{s} \xi_{n}^{\prime}(x) \psi_{n}^{\prime}(m x)} \\
b_{n}=\frac{\psi_{n}^{\prime}(x) \psi_{n}(m x)-m \psi_{n}(x) \psi_{n}^{\prime}(m x)+i \omega k^{-1} \mu_{0} \sigma_{s} \psi_{n}(x) \psi_{n}(m x)}{\xi_{n}^{\prime}(x) \psi_{n}(m x)-m \xi_{n}(x) \psi_{n}^{\prime}(m x)+i \omega k^{-1} \mu_{0} \sigma_{s} \xi_{n}(x) \psi_{n}(m x)}
\end{gathered}
$$

where $\psi_{n}(x)=x j_{n}(x)$ and $\xi_{n}(x)=x h_{n}^{1}(x)$, in which $j_{n}(x)$ and $h_{n}^{1}(x)$ are respectively the first-order Bessel function and spherical Hankel

5 function. $m$ is the relative refractive index. $i=\sqrt{-1} \cdot \omega=2 \pi c / \lambda$ is the circular frequency of the EM wave and $k=2 \pi \lambda / c$ is the wave number. $\mu_{0}=$ $1.256 \times 10^{-6}$ is the permeability of a vacuum. $\sigma_{s}$ is the surface conductivity analogous to the (bulk) conductivity and it may be complex and depend on the frequency. Bohren and Hunt (Bohren and Hunt, 2011) and Klačka et al. (Klačka and Kocifaj, 2007; Klačka. and Kocifaj, 2010) studied $\sigma_{s}$, usually expressed as $\sigma_{s}=\frac{i \sigma q_{m}}{\omega+\gamma_{s}}$. Here $\sigma$ is the surface charge density, $q_{m}=1.7587 \times 10^{12} \mathrm{C} / \mathrm{kg}$ is the charge-mass ratio of an element charge, which is taken as the electron in this paper, and $\gamma_{s}$ is equal to $k_{B} T / \hbar$, with $T$ being the temperature of the particle and $k_{B}=1.38 \times$ $1010^{-23} \mathrm{~J} / \mathrm{K}$ and $\hbar=1.0546 \times 10^{-34} \mathrm{Js}$ respectively being Boltzmann's constant and Planck's constant (Klačka and Kocifaj, 2007).

Furthermore, the extinction coefficient and backscattering coefficient of the atmospheric particles per unit volume can be calculated as

$$
\begin{gathered}
\sigma_{e x t}=\int_{r_{\min }}^{r_{\max }} \pi r^{2} Q_{e x t} n(r) d r \\
\beta=\int_{r_{\min }}^{r_{\max }} \pi r^{2} Q_{b a c} n(r) d r
\end{gathered}
$$

where $r_{\min }$ and $r_{\text {max }}$ are respectively the minimum and maximum particle radii. $n(r)$ is the number density distribution of the atmospheric particles, which can be substituted into (1) and (2) to calculate the RPR and investigate the effect of the charges carried by particles on the RPR when the surface charge density or the surface conductivity is known.

\section{Results and discussions}

There are many important particles in the atmosphere that affect the weather or pollute the air, such as haze particles, sand and dust particles, cloud particles, and raindrops. There is thus an interest in detecting these particles. The particles are not equal in size; e.g.,, haze particles are not larger than $10^{-6} \mathrm{~m}$ in diameter, cloud particles are not larger than $10^{-5} \mathrm{~m}$ in diameter, sand/dust particles are not larger than $10^{-4} \mathrm{~m}$ in diameter, and raindrops

20 particles are not larger than $10^{-2} \mathrm{~m}$ in diameter (Hess et al., 1998; Wolfson, 1979; Ahmed, 2008; Aoki et al., 2016). However, all these particles obey a log-normal distribution in size, as shown in Fig. 2. The mathematical expression is 
Atmos. Meas. Tech. Discuss., https://doi.org/10.5194/amt-2017-384

Manuscript under review for journal Atmos. Meas. Tech.

Discussion started: 28 November 2017

(c) Author(s) 2017. CC BY 4.0 License.

(c) (i)

\section{Atmospheric \\ Measurement \\ Techniques \\ Discussions}

$$
n(r)=\frac{d N}{d \ln r}=\frac{N}{\sqrt{2 \pi} \ln \sigma_{r}} \exp \left[-\frac{\ln r-\ln \bar{r}}{2\left(\ln \sigma_{r}\right)^{2}}\right],
$$

where $N$ is the total number of particles per unit volume and $\bar{r}$ and $\sigma_{r}$ are respectively the mean value and standard deviation of the particle radius.

Particles in different size regions are usually detected by different radar systems, and the frequencies of the EM waves emitted by the radar systems are usually different; e.g., S-band radar $(f=2-4 \mathrm{GHz})$ is used to detect raindrops especially for strong rainfall (Yuter and Jr, 2010), X-band radar $(f=$

5 8-12 GHz) is used to detect dust/sand particles (Wang, 2010), and W-band radar $(f=80-100 \mathrm{GHz}$ ) is used to detect cloud particles (Sassen and

Liao, 1996), while lidar $\left(f=5.6 \times 10^{5} \mathrm{GHz}\right)$ is used to detect smaller particles, such as haze and smoke particles (Collis and Uthe, 1972).

We next investigate the effect of charges carried by particles on the RPR. The ratio of RPR(c) considering the charges carried by the particles to $\mathrm{RPR}(0)$ without considering charges is shown for different particle systems in Fig. 3, where four surface charge densities $\sigma=0 \mathrm{C} / \mathrm{m}^{2}, \sigma=$ $-2 \times 10^{-4} \mathrm{C} / \mathrm{m}^{2}, \sigma=-6 \times 10^{-4} \mathrm{C} / \mathrm{m}^{2}$ and $\sigma=-10^{-3} \mathrm{C} / \mathrm{m}^{2}$ are considered within the charge range mentioned above. Figure 3 shows that the charges carried by the particles result in $\mathrm{RPR}(\mathrm{c})$ being greater than $\mathrm{RPR}(0)$, and $\mathrm{RPR}(\mathrm{c})$ increases more as the surface charge density increases for a given particle radius. The increment of $\mathrm{RPR}(\mathrm{c})$ is not linearly dependent on the particle radius in the results for the detection of haze particles by lidar, detection of cloud particles by W-band radar, detection of sand/dust particles by X-band radar, and detection of raindrops by S-band radar, as shown in Figs. 3(a)-3(d). The increment of the RPR due to surface charges carried by the particles is therefore related to both the particle size and radar wavelength, which agrees with backscattering results reported in the literature (Klačka and Kocifaj, 2007; Kocifaj et al., 2015).

15 In the calculation, the frequencies of the lidar wave, W-band wave, X-band wave, and S-band wave are respectively taken as $5.6 \times 10^{5}, 1.1 \times 10^{2}, 8$, and $4 \mathrm{GHz}$.

The RPR(c)/RPR(0) ratios of sand/dust particles and cloud particles detected by S-band radar, X-band radar, W-band radar, and lidar are shown in Figs. 4 (a)-4(b), where the surface charge density is $\sigma=-10^{-3} \mathrm{C} / \mathrm{m}^{2}$. Figure 4 shows that the increment of RPR due to the charges carried by the same particles depends on the emission frequency of the radar system. $\operatorname{RPR}(\mathrm{c}) / \operatorname{RPR}(0)$ of the same particle with the same surface charge density increases as the radar emission frequency decreases as shown in Fig. 4(a). Meanwhile, Fig. 4(b) shows that RPR(c)/RPR(0) for the W-band radar is higher than that for the S-band radar and X-band radar, although the emission frequency of the former radar is higher than that of the latter. Because 
Atmos. Meas. Tech. Discuss., https://doi.org/10.5194/amt-2017-384

Manuscript under review for journal Atmos. Meas. Tech.

Discussion started: 28 November 2017

(c) Author(s) 2017. CC BY 4.0 License.

(c) (i)

\section{Atmospheric \\ Measurement \\ Techniques \\ Discussions}

the relative refractive index of the particle material depends on the emission frequency of the EM wave (Jiang and Wu, 2010; Dou and Xie, 2017), the increment of RPR due to charges carried by the particles is also related to the relative refractive index.

Figures 3 and 4 show that the charges carried by particles will increase the receiving power if the radar is well designed when the particle number density $n(r)$ or particle number per unit $N$ are given. In fact, $n(r)$ or $N$ might not be known and usually need to be reversely derived

5 according to the receiving power. However, the effect of the charges is not considered in the current radar design. The power received by the radar is therefore attributed to the power of scattering by the particles including the contribution of charges to the received power, which could result in the overestimation of particle properties, such as $N$. We denote the particle number density determined by radar considering charges carried by the particles as $N(c)$, and that without considering charges as $N(0)$. The $N(c) / N(0)$ ratio is plotted in Fig. 5 is to show the effect of the charge carried by the particles. Figure 5 shows that $N(c) / N(0)$ for a given radar decreases as the surface charge density increases, which means that the particle number

10 density will be overestimated when the effect of the charges carried by particles is not considered in the reverse calculation. The overestimation is assumed as $[1-N(c) / N(0)] \times 100 \%$. The overestimation is about $2.05 \%$ when $\sigma=-5 \times 10^{-4} \mathrm{C} / \mathrm{m}^{2}$, while it is about $5.43 \%$ when $\sigma=$ $-10^{-3} \mathrm{C} / \mathrm{m}^{2}$ for S-band radar. $N(c) / N(0)$ for a different radar is different for the same surface charge density as shown in Fig. 5 , which means the overestimation also depends on the emission frequency of the radar. The overestimations of the particle number density for four surface charge densities determined by S-band radar, X-band radar, W-band radar, and lidar are given in Table 1. The table shows that the overestimation of the

15 particle number density of sand particles detected by lidar is low, even though the charge surface density is taken as $\sigma=-10^{-3} \mathrm{C} / \mathrm{m}^{2}$. We therefore suggest that it is better to detect sand particles by lidar to avoid the effect of charges carried by sand particles.

On the basis of the RPR, many other properties of the atmospheric particles need to be reversely calculated, not only the particle number density, with these properties also affected by charges carried by the particles, and further study is thus expected.

\section{Conclusions}

The effect of charges carried by atmospheric particles on the RPR was investigated. It was found that charges carried by particles result in the RPR being greater than the RPR without consideration of the contribution of the charges to the receiving power, and the RPR increases with the 
Atmos. Meas. Tech. Discuss., https://doi.org/10.5194/amt-2017-384

Manuscript under review for journal Atmos. Meas. Tech.

Discussion started: 28 November 2017

(c) Author(s) 2017. CC BY 4.0 License.

(c) (i)

\section{Atmospheric \\ Measurement \\ Techniques \\ Discussions}

surface charge density for a given particle radius. The increment of RPR due to the surface charges carried by particles is also related to both the particle size and radar emission frequency.

According to the RPR when considering charges carried by particles, the estimation of the particle number density for sand/dust weather using radar systems of different bands was discussed, and it was found that the particle number density can be overestimated when not considering the contribution of the charges carried by the particles to the receiving power. The overestimation depends on the surface charge density and frequency of the radar. Calculation results of the overestimation for the sand particle number density indicate that the effect of charges carried by particles can be ignored when particle properties are determined by lidar.

At present, the contribution of charges to the received power is not considered in radar detection, resulting in the overestimation of particle properties. Further study is required to consider the effect of charges carried by particles to reasonably select radar bands and to design radar systems, allowing more accurate measurement of the atmosphere.

Acknowledgement: This research is supported by the Innovative Research Group of the National Natural Science Foundation of China (No. 11421062) and by the grant from the National Natural Science Foundations of China (Nos.11472122).

\section{References}

15 Ahmed, A. S.: Role of particle-size distributions on millimetre-wave propagation in sand/dust storms, IEE Proceedings H Microwaves, Antennas and Propagation, 134, 55-59, 2008.

Aoki, M., Iwai, H., Nakagawa, K., Ishii, S., and Mizutani, K.: Measurements of rainfall velocity and raindrop size distribution using coherent Doppler lidar, Journal of Atmospheric \& Oceanic Technology, 33, 2016.

Barrett, E. W., and Bendov, O.: Application of the Lidar to Air Pollution Measurements, Journal of Applied Meteorology, 6, 500-515,

201967. 
Atmos. Meas. Tech. Discuss., https://doi.org/10.5194/amt-2017-384

Manuscript under review for journal Atmos. Meas. Tech.

Discussion started: 28 November 2017

(c) Author(s) 2017. CC BY 4.0 License.

(c) (i)

\section{Atmospheric \\ Measurement \\ Techniques \\ Discussions}

Bohren, C. F., and Hunt, A. J.: Scattering of electromagnetic waves by a charged sphere, Canadian Journal of Physics, 55, 1930-1935, 2011.

Chiou, M. M., and Kiang, J. F.: PWE-based Radar Equation to Predict Backscattering of Millimeter-Wave in a Sand-and-Dust Storm, IEEE Transactions on Antennas \& Propagation, PP, 1-1, 2017.

5 Collis, R. T.: Lidar, Advances in Geophysics, 13, 113-139, 1970.

Collis, R. T. H., and Uthe, E. E.: Mie scattering techniques for air pollution measurement with lasers, Opto-electronics, 4, 87-99, 1972.

Collis, R. T. H.: Lidar: A new atmospheric probe, Quarterly Journal of the Royal Meteorological Society, 92, 220-230, 2010.

Dou, X., and Xie, L.: Electromagnetic wave attenuation due to the charged particles in dust\&sand (DUSA) storms, Journal of

10 Quantitative Spectroscopy and Radiative Transfer, 196, 169-175, 2017.

Fukao, S., Hamazu, K., and Doviak, R. J.: Radar for meteorological and atmospheric observations, Springer, 2014.

Gaussiat, N., Sauvageot, H., and Illingworth, A. J.: Cloud Liquid Water and Ice Content Retrieval by Multiwavelength Radar, Journal of Atmospheric \& Oceanic Technology, 20, 1264-1275, 2003.

Hess, M., Koepke, P., and Schult, I.: Optical Properties of Aerosols and Clouds: The Software Package OPAC, Bulletin of the

15 American Meteorological Society, 79, 831-844, 1998.

HR, P., and JD., K.: In: Microphysics of clouds and precipitation, the Netherlands: Kluwer Academic Publishers, 2003.

Hu, Q., and Xie, L.: Scattering phase function of a charged spherical particle, Applied Optics, 54, 8439-8443, 2015.

Jiang, J. H., and Wu, D. L.: Ice and water permittivities for millimeter and sub-millimeter remote sensing applications, Atmospheric Science Letters, 5, 146-151, 2010.

20 Klačka, J., and Kocifaj, M.: Scattering of electromagnetic waves by charged spheres and some physical consequences, Journal of Quantitative Spectroscopy \& Radiative Transfer, 106, 170-183, 2007. 
Atmos. Meas. Tech. Discuss., https://doi.org/10.5194/amt-2017-384

Manuscript under review for journal Atmos. Meas. Tech.

Discussion started: 28 November 2017

(c) Author(s) 2017. CC BY 4.0 License.

(c) (i)

\section{Atmospheric \\ Measurement \\ Techniques \\ Discussions}

Klačka, J., Kocifaj, M., Kundracik, F., Videen, G., and Kohút, I.: Generalization of electromagnetic scattering by charged grains through incorporation of interband and intraband effects, Optics Letters, 40, 5070-5073, 2015.

Klačka., J., and Kocifaj, M.: On the Scattering of Electromagnetic Waves by a Charged Sphere, Progress in Electromagnetics Research, 109, 17-35, 2010.

5 Kocifaj, M., Videen, G., and Klačka, J.: Backscatter in a cloudy atmosphere as a lightning-threat indicator, Journal of Quantitative Spectroscopy \& Radiative Transfer, 150, 175-180, 2015.

Middleton, N. J.: Desert dust hazards: A global review, Aeolian Research, 24, 53-63, 2017.

Mona, L., Liu, Z., and Müller, D.: Lidar Measurements for Desert Dust Characterization: An Overview, Advances in Meteorology, 2012, 1449-1458, 2012.

10 Muller, H., and Quenzel, H.: Information content of multispectral lidar measurements with respect to the aerosol size distribution, Applied Optics, 24, 648, 1985.

Musa, A., Bashir, S. O., and Abdalla, A. H.: Review and assessment of electromagnetic wave propagation in sand and dust storms at microwave and millimeter wave bands — Part I, Progress in Electromagnetics Research M, 40, 91-100, 2014.

Sassen, K., and Liao, L.: Estimation of Cloud Content by W-Band Radar, Journal of Applied Meteorology, 35, 932-938, 1996.

15 Tao, G., Zhang, X. B., and Wulan: A seasonal forecast scheme for spring dust storm predictions in Northern China, Meteorological Applications, 17, 433-441, 2010.

Wang, J. X.: Doppler Weather Radar in Sand and Dust Weather Monitoring Application, Coal Technology, 2010.

Wilson, J. W., and Brandes, E. A.: Radar Measurement of Rainfall-A Summary, Bulletin of the American Meteorological Society, 60, 1048-1060, 1979.

20 Wolfson, N.: The Droplet Size Distribution in Cumulus Clouds in the $0.1 \mu \mathrm{m}<\mathrm{r}<15 \mu \mathrm{m}$ Range, Journal of the Atmospheric Sciences, 36, 1053-1060, 1979. 
Atmos. Meas. Tech. Discuss., https://doi.org/10.5194/amt-2017-384

Manuscript under review for journal Atmos. Meas. Tech.

Discussion started: 28 November 2017

(c) Author(s) 2017. CC BY 4.0 License.

(c) (1)
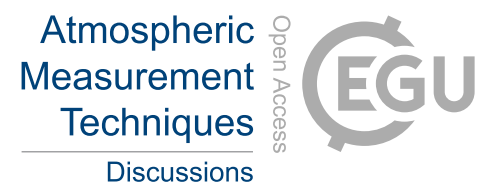

Yuter, S. E., and Jr, R. A. H.: Microphysical modes of precipitation growth determined by S-band vertically pointing radar in orographic precipitation during MAP, Quarterly Journal of the Royal Meteorological Society, 129, 455-476, 2010.

Zhao, S., Yu, Y., Xia, D., Yin, D., He, J., Liu, N., and Li, F.: Urban particle size distributions during two contrasting dust events originating from Taklimakan and Gobi Deserts, Environmental Pollution, 207, 107-122, 2015.

5 Zheng, X., He, L., and Zhou, Y.: Theoretical model of the electric field produced by charged particles in windblown sand flux, Journal of Geophysical Research Atmospheres, 109, 1265-1277, 2004.

Zheng, X. J., Huang, N., and Zhou, Y. H.: Laboratory measurement of electrification of wind-blown sands and simulation of its effect on sand saltation movement, Journal of Geophysical Research Atmospheres, 108, 231-231, 2003.

Zhou, J., and Xie, L.: Effect of net surface charge on particle sizing and material recognition by using phase Doppler anemometry,

10 Applied Optics, 50, 379-386, 2011.

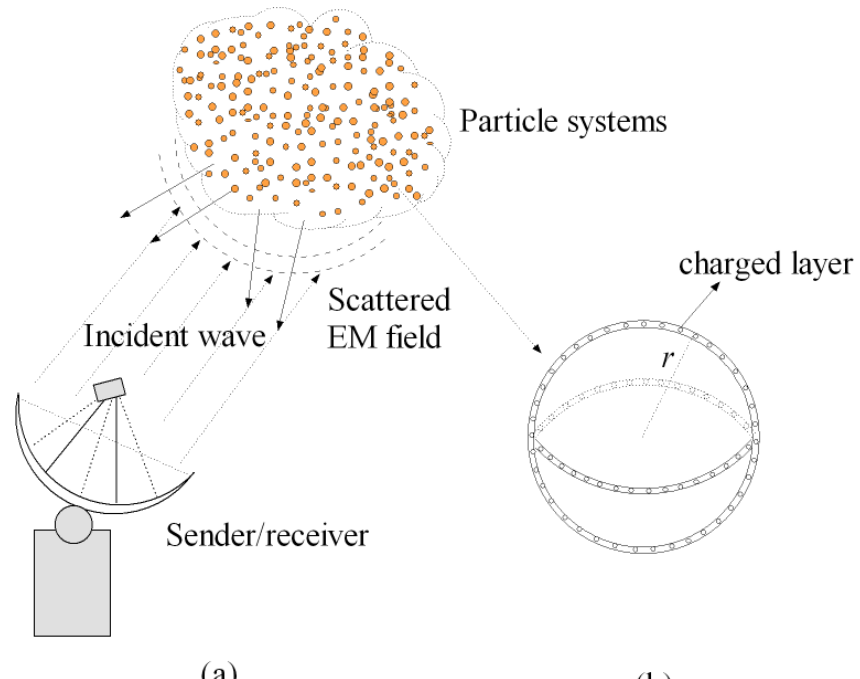

Fig. 1 (a) Schematic of the radar detection of an atmospheric particle system; (b) surface-charged atmospheric particle. 
Atmos. Meas. Tech. Discuss., https://doi.org/10.5194/amt-2017-384

Manuscript under review for journal Atmos. Meas. Tech.

Discussion started: 28 November 2017

(c) Author(s) 2017. CC BY 4.0 License.

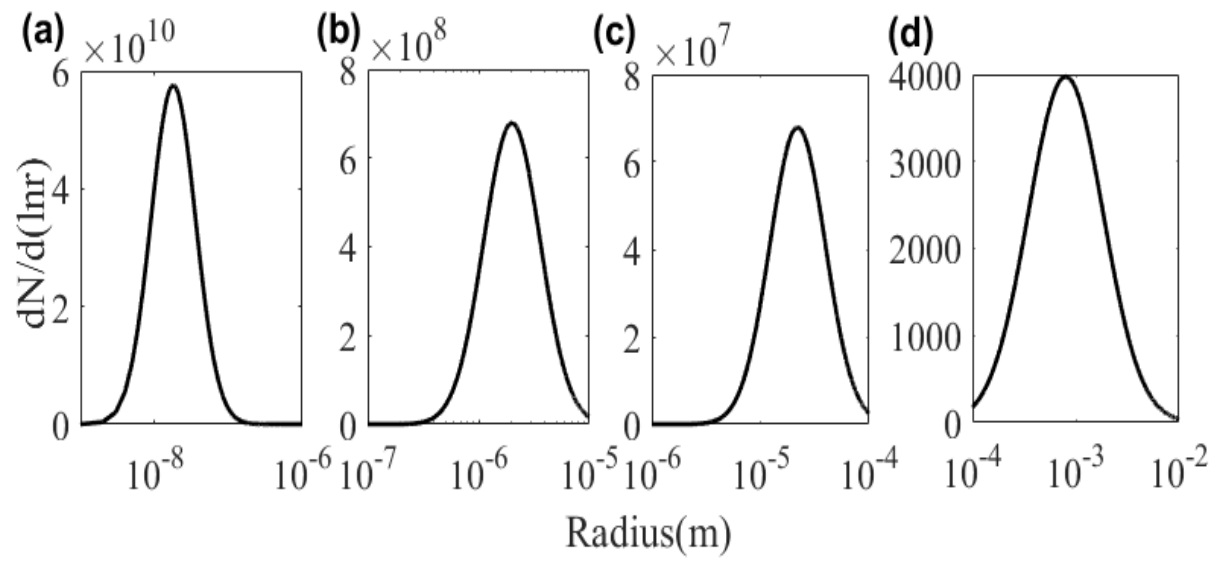

Fig. 2 Size distributions of four particle types: (a) haze particles, (b) cloud particles, (c) dust/sand particles, (d) rainfall particles.
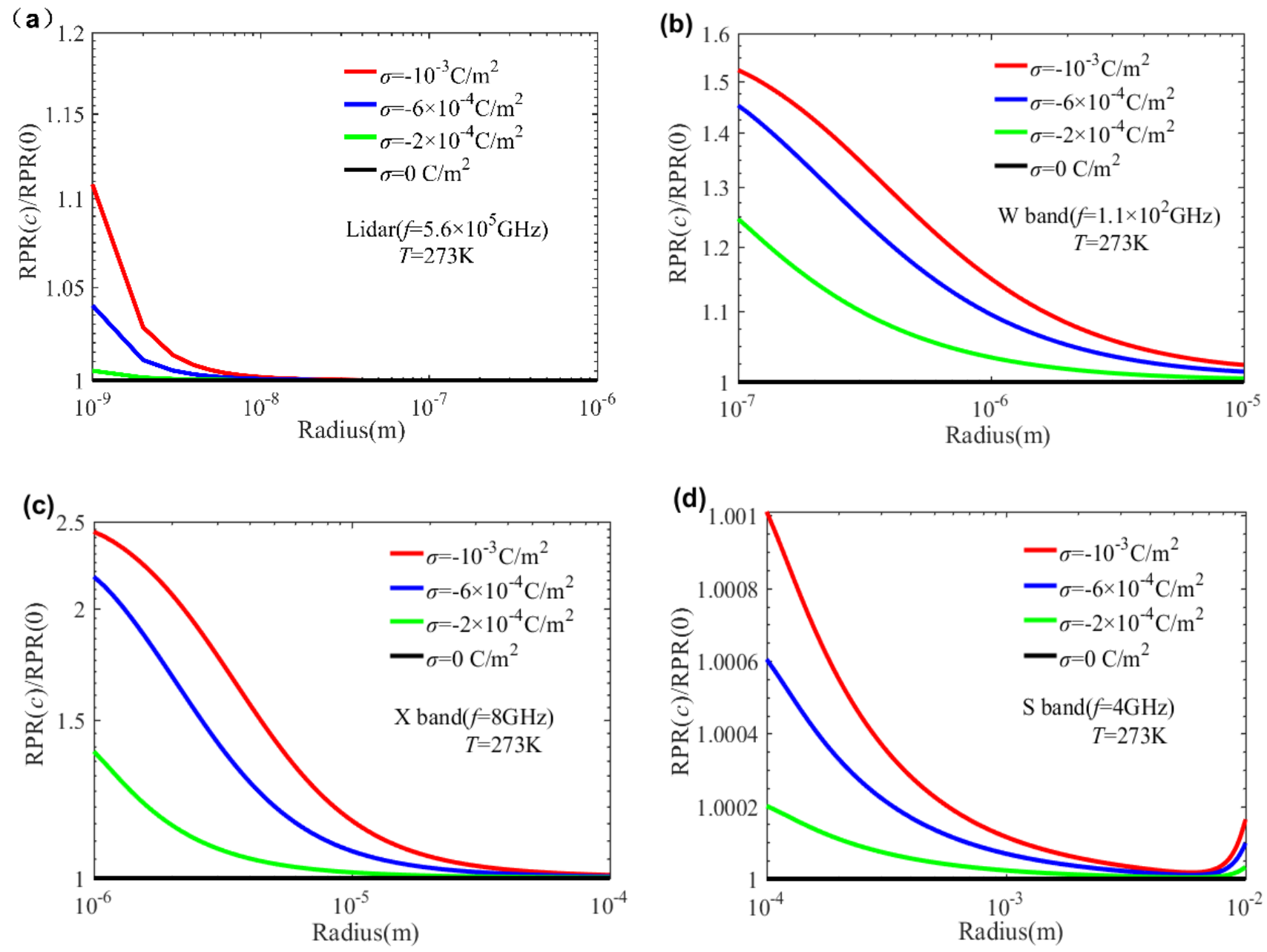
Atmos. Meas. Tech. Discuss., https://doi.org/10.5194/amt-2017-384

Manuscript under review for journal Atmos. Meas. Tech.

Discussion started: 28 November 2017

(c) Author(s) 2017. CC BY 4.0 License.

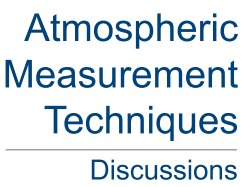

(c) (1)

Fig. 3 Ratio of RPR(c) considering the charges carried by the particles to RPR(0) without considering charges versus the particle radius for different surface charge densities: (a) haze particles detected by lidar, (b) cloud particles detected by W-band radar, (c) sand/dust particles detected by X-band radar, (d) raindrops detected by S-band radar.
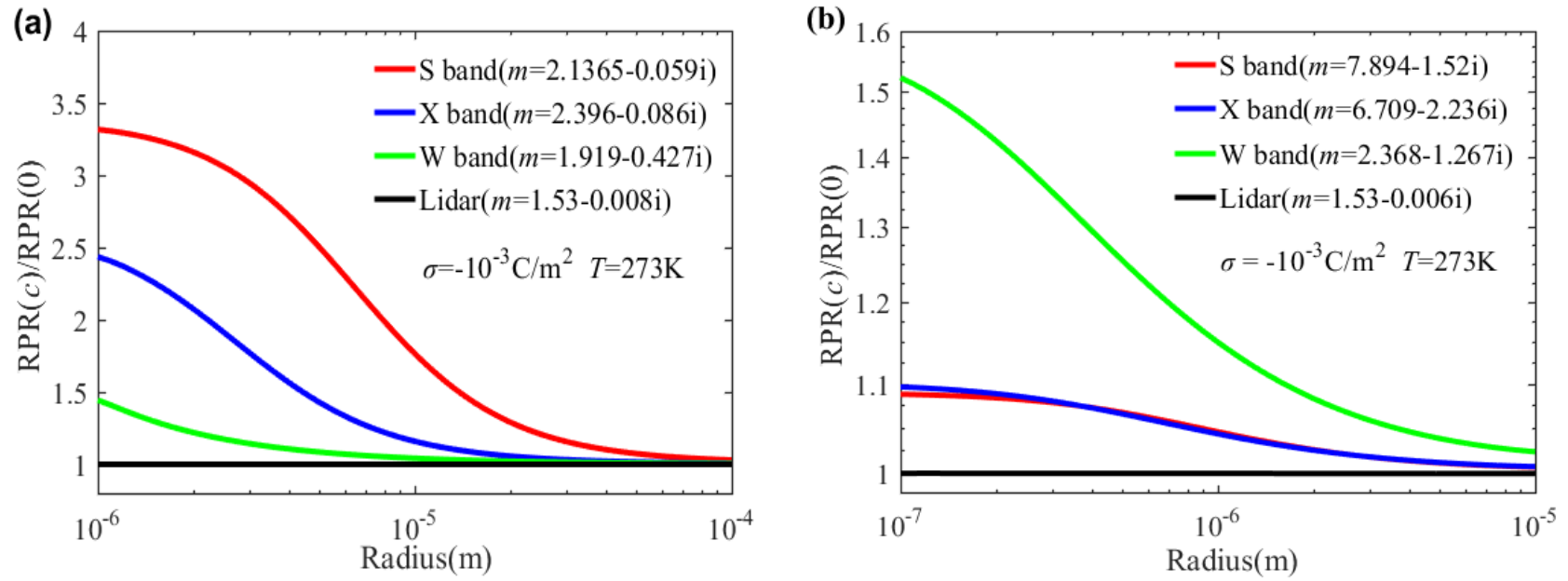

Fig. 4 RPR(c)/RPR(0) ratios of sand/dust particles (a) and cloud particles (b) versus the particle radius for radars of different bands.

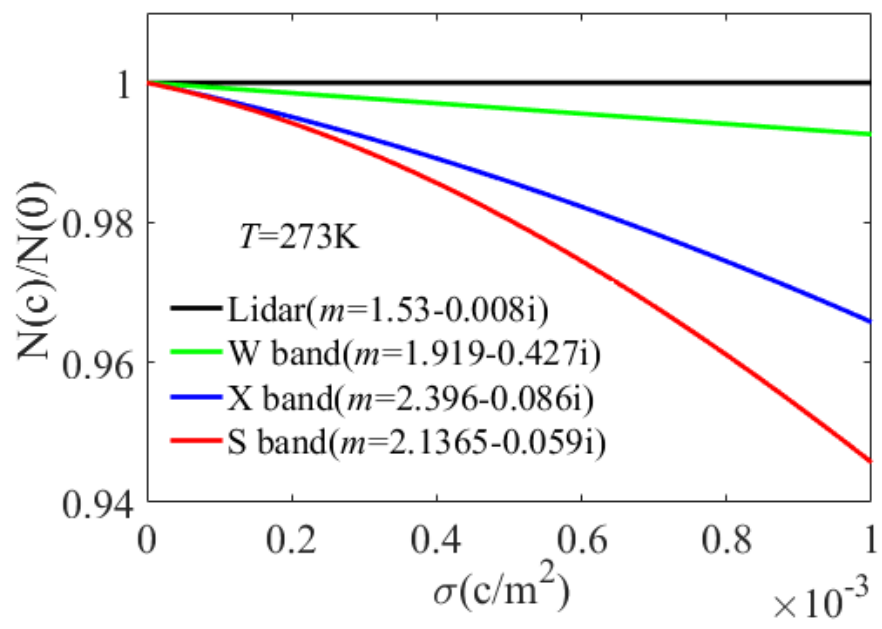

Fig. 5 Ratio of $N(c)$ considering the charges carried by particles to $N(0)$ without considering charges versus the particle surface charge density for radars of different bands. 
Atmos. Meas. Tech. Discuss., https://doi.org/10.5194/amt-2017-384

Manuscript under review for journal Atmos. Meas. Tech.

Discussion started: 28 November 2017

(c) Author(s) 2017. CC BY 4.0 License.

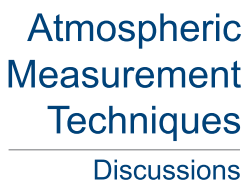

(c) (1)

Table 1. Overestimations of the sand particle number density for four surface charge densities and radars of different bands

\begin{tabular}{|c|c|c|c|c|}
\hline$\sigma$ & $-10^{-5} \mathrm{C} / \mathrm{m}^{2}$ & $-10^{-4} \mathrm{C} / \mathrm{m}^{2}$ & $-5 \times 10^{-4} \mathrm{C}^{2} \mathrm{~m}^{2}$ & $-10^{-3} \mathrm{C} / \mathrm{m}^{2}$ \\
\hline frequency & $0.0221 \%$ & $0.25 \%$ & $2.05 \%$ & $5.43 \%$ \\
\hline $\mathrm{X}(f=4 \mathrm{GHHz})$ & $0.0222 \%$ & $0.24 \%$ & $1.47 \%$ & $3.43 \%$ \\
\hline $\mathrm{W}(f=110 \mathrm{GHz})$ & $0.0075 \%$ & $0.075 \%$ & $0.38 \%$ & $0.74 \%$ \\
\hline Lidar $\left(f=5.6 \times 10^{5} \mathrm{GHz}\right)$ & 0 & 0 & $0.001 \%$ & $0.005 \%$ \\
\hline
\end{tabular}

